\title{
Article \\ One-Pot Synthesis of Bright Blue Luminescent N-Doped GQDs: Optical Properties and Cell Imaging
}

\author{
Huaidong Wang ${ }^{1}$, Chong $\mathrm{Qi}^{1}$, Ailing Yang ${ }^{1, *}$, Xiaoxu Wang ${ }^{2}$ and Jie $\mathrm{Xu}^{2}$ \\ 1 College of Physics \& Optoelectronic Engineering, Ocean University of China, Qingdao 266100, China; \\ wanghuai-dong@stu.ouc.edu.cn (H.W.); qichong@stu.ouc.edu.cn (C.Q.) \\ 2 College of Food Science \& Engineering, Ocean University of China, Qingdao 266003, China; \\ wangxx0416@163.com (X.W.); xujie9@ouc.edu.cn (J.X.) \\ * Correspondence: ailingy@ouc.edu.cn
}

Citation: Wang, H.; Qi, C.; Yang, A.; Wang, X.; Xu, J. One-Pot Synthesis of Bright Blue Luminescent N-Doped GQDs: Optical Properties and Cell Imaging. Nanomaterials 2021, 11, 2798. https://doi.org/10.3390/ nano11112798

Academic Editor: Antonio

Di Bartolomeo

Received: 25 September 2021

Accepted: 19 October 2021

Published: 22 October 2021

Publisher's Note: MDPI stays neutral with regard to jurisdictional claims in published maps and institutional affiliations.

\section{Copyright: (C) 2021 by the authors.} Licensee MDPI, Basel, Switzerland. This article is an open access article distributed under the terms and conditions of the Creative Commons Attribution (CC BY) license (https:/ / creativecommons.org/licenses/by/ $4.0 /)$.

\begin{abstract}
High fluorescent graphene quantum dots (GQDs) are promising in bioimaging and optoelectronics. In this paper, bright blue fluorescent N-doped GQDs were synthesized using a ultrasonicassisted hydrothermal method. The morphology, structure, surface chemistry, optical properties, and stability subject to photo-bleaching, temperature, $\mathrm{pH}$ and preservation period for the N-GQDs were investigated in detail using various microscopy and spectroscopy techniques. The results showed that the N-GQDs possessed an average size of $2.65 \mathrm{~nm}, 3.57 \% \mathrm{~N}$ doping, and up to $54 \%$ quantum yield (QY). The photoluminescence (PL) spectra of the N-GQDs are excitation dependent when excited in the range of 300-370 $\mathrm{nm}$ and excitation independent in the range of 380-500 $\mathrm{nm}$ for the core and surface states emission. The N-GQDs showed excellent photo-bleaching resistance and superior photo-stability. At room temperature and in the $\mathrm{pH}$ range of 3-8, the fluorescence of the N-GQDs was almost invariable. The N-GQDs can be stably preserved for at least 40 days. The average decay lifetime of the N-GQDs was $2.653 \mathrm{~ns}$, and the radiative and nonradiative decay rate constants were calculated to be $2.04 \times 10^{8} \mathrm{~s}^{-1}$ and $1.73 \times 10^{8} \mathrm{~s}^{-1}$, respectively. The PL mechanism was qualitatively explained. The N-GQDs was used for cell imaging, and it showed good results, implying great potential applications for bioimaging or biomarking.
\end{abstract}

Keywords: ultrasonic-assisted hydrothermal; nitrogen doped graphene quantum dots; optical properties; photo-stability; cell imaging

\section{Introduction}

Graphene (Gr) and its derivative graphene oxide (GO) have been a hot research direction in materials science in recent years [1-7]; however, applications of Gr in the fields of bioimaging and optoelectronics have been limited, because Gr is a zero-band-gap semiconductor and a non-fluorescent substance. Graphene quantum dots (GQDs) are small sheets of Gr with lateral size of less than $10 \mathrm{~nm}$, with oxygen-containing groups at the edges. As a result of the quantum confinement effect and the lateral effect, GQDs are fluorescent matter. In addition to this, GQDs possess other outstanding advantages, such as their being green, nontoxic, chemically inert, possessing good aqueous solubility and excellent biocompatibility, and lending themselves to easy modification, rendering GQDs as one of the most promising fluorescent nanomaterials, superior to conventional fluorescent organic dyes and luminescent inorganic quantum dots, with extensive potential applications in bioimaging [8-10], as drug carriers [11], and in disease diagnosis [12], optical sensors [13-15], solar cells [16-18], light emitting diodes [19], and photocatalysts [20]. Several methods have been developed for the fabrication of GQDs. Generally, these approaches can be classified into two types: top-down and bottom-up. Top-down methods are mainly based on cutting the large carbon materials into nanoparticles (NPs), such as through the chemical exfoliation of graphite NPs [21] and the hydrothermal cutting of oxidized graphene sheets [22]. Topdown methods may produce some toxic products [23] that are difficult to completely 
remove in post-treatment procedures, thus leading to environmental pollution, causing health hazards to humans, and also limiting their widespread use. Bottom-up approaches use small molecules containing $\mathrm{C}, \mathrm{H}$, and $\mathrm{O}$ as precursors, via solid phase pyrolysis or hydrothermal condensation, to obtain GQDs [24,25].

Nitrogen-doped GQDs (N-GQDs) may improve the fluorescent quantum yield (QY) by adjusting the photoluminescence (PL) range. This enhances biocompatibility, and therefore, the properties of N-GQDs have attracted a significant amount of research interest [26]. The direct pyrolysis of small molecules in solid phase [27-29] and via the hydrothermal route $[12,30,31]$ has been used to prepare N-GQDs. The direct pyrolysis of small molecules in solid phase to obtain N-GQDs is simple and quick, but small molecules are easily over-carbonized, and large particles can readily be produced, leading to a product with a wide size distribution and complex post-treatment procedures. The negative effects the direct pyrolytic method described above restrict its widespread use in the preparation of N-GQDs. The hydrothermal route seems to be the key to solving the problems inherent in the direct pyrolysis of small molecules in solid phase [32]. The ultrasonic hydrothermal method has distinct advantages with respect to maintaining homogeneous reaction conditions to prevent the N-GQDs from agglomerating, as well as providing a shorter reaction time, milder reaction conditions, lower energy consumption, better stability, and good reproducibility. Thus, in this paper, an ultrasonic hydrothermal method was used to synthesize N-GQDs in one step, with citric acid (CA) as a precursor and L-glutamic (L-Glu) for $\mathrm{N}$ doping and as a passivant. Compared to the two-step approach (first fabrication of GQDs, then amino-modification), the one-step strategy is easier and saves time; more importantly, the L-Glu functionalized GQDs have the benefit of decreasing the surface defects of GQDs, thus enhancing the QY and stability, and improving biocompatibility. The as-prepared N-GQDs were characterized in detail and used for cell imaging. The results indicated that the N-GQDs possessed excellent photo-physical properties and were effective in BV2 cell imaging. In this regard, this new strategy overcomes the limitations of existing N-GQDs, by reducing the surface defects, increasing the QY and stability, and improving biocompatibility.

\section{Experimental Section}

\subsection{Materials and Characterization}

L-Glu, CA and Rhodamine B reagents were all of analytical grade and were purchased from Aladdin Reagent Co., Ltd. (Shanghai, China). Ultrapure water $(18.2 \mathrm{M} \Omega \cdot \mathrm{cm})$ was used as a solvent. Propidium iodide (95\%), Dulbecco's modified Eagle medium (DMEM) and fetal bovine serum (FBS) were bought from Gibco (Gaithersburg, MD, USA). Penicillin and streptomycin sulfate were purchased from Invitrogen.

An YZUR-100 (Shanghai Yan Zheng, Shanghai, China) ultrasonic hydrothermal reactor $(220 \mathrm{~V})$ was used to synthesize N-GQDs; the ultrasonic power could be adjusted within $250 \mathrm{~W}$, and the stirring speed was $200 \mathrm{rad} / \mathrm{min}$; the pressure in the cavity was controlled between 0.84-0.88 MPa. The ultraviolet-visible (UV-Vis) absorption spectra were determined using a UH5300 spectrophotometer (Hitachi, Japan) at room temperature. PL spectra were measured using a FluoraMAX-4 fluorescent spectrometer (Horiba JY, Edison, NJ, USA) with excitation/emission slit width of $2 / 3 \mathrm{~nm}$. The crystalline structure of N-GQD solid powder was characterized using an X-ray diffractometer (XRD, Bruker D8 ADVANCE, BRUKER AXS, Germany) with $\mathrm{Cu}-\mathrm{K} \alpha$ radiation $(\lambda=1.5406 \AA)$. A high-resolution transmission electron microscope (HRTEM, Tecnai G2 F30 Hillsboro, OR, USA) was used to observe the morphology and lattice of the N-GQDs prepared on an ultra-thin carbon film. The size distribution of the N-GQDs was analyzed with Image J software. By coating the diluted N-GQDs on freshly dissociated mica, the surface morphology and thickness of N-GQDs were characterized using an atomic force microscope (AFM, Seiko-SPA400, Tokyo, Japan) with ScanAsys atomic imaging optimization technology. Fourier transform infrared (FTIR) spectroscopy was employed using a Nicolet iN10 FTIR spectrometer (Thermo Fisher Scientific, Waltham, MA, USA) with a resolution of $4 \mathrm{~cm}^{-1}$ from 4000 to $500 \mathrm{~cm}^{-1}$. The 
test sample was prepared by grinding, mixing then pressing of $2 \mathrm{mg}$ powder of N-GQDs and $100 \mathrm{mg}$ KBr powder. X-ray Photoelectron Spectroscopy (XPS) with a multifunctional imaging electron spectrometer (Thermo ESCALAB 250XI, America, with a radiation source Al $\mathrm{K} \alpha-1486.6 \mathrm{eV}$ ) was used to analyze the elemental compositions and chemical bonds of the obtained N-GQDs. The fluorescence lifetime of the N-GQDs was measured using the time-correlated single photon counting (TCSPC) technique, an Edinburgh F900 time-resolved fluorescence spectrometer (FLS-980, Edinburgh, UK) with an LED excitation source $(370 \mathrm{~nm})$, and an electrically cooled red sensitive R928P photon-counting photomultiplier tube detector to obtain the fluorescence lifetime, with a monitor emission wavelength of $440 \mathrm{~nm}$. An incubator (Thermo Fisher Scientific, Waltham, MA, USA) was employed to culture BV2 cells. Cell imaging was performed using a confocal laser scanning microscope (LSM, Nikon A1R HD25, Tokyo, Japan) with three semiconductor lasers (405, 488, and $532 \mathrm{~nm})$.

\subsection{Preparation of $N-G Q D s$}

The ultrasonic-assisted method was used to fabricate the N-GQDs as shown in Scheme 1. The natural organic acid CA provided the carbon source, and the natural amino acid L-Glu supplied the amino group and part of the carbon source to achieve nitrogen doping. In the fabrication process, the reaction temperature $\left(180^{\circ} \mathrm{C}\right)$ was higher than the boiling point of CA $\left(160{ }^{\circ} \mathrm{C}\right)$, but lower than that of the L-Glu $\left(225^{\circ} \mathrm{C}\right)$; therefore, CA was pyrolyzed, dehydrated and condensed to form GQDs. GQDs possess $\mathrm{COOH}$ and $\mathrm{OH}$ at the surfaces and edges; through the dehydration reaction, L-GLu was linked to GQDs, so the GQDs were functionalized by L-Glu in a single step, which is of great benefit for decreasing the surface defects on GQDs, thus enhancing the QY $[33,34]$. The amino groups in GQDs make them useful in the field of biomedicine [35]. The synthesis was optimized step by step (the experimental process is shown in the Supporting Information, see Figure S1 and Table S1). Typically, $3.6 \mathrm{~g} \mathrm{CA}$ and $1.8 \mathrm{~g}$ L-Glu were dispersed into $30 \mathrm{~mL}$ deionized water; the solution was heated up to $180{ }^{\circ} \mathrm{C}$ in the ultrasonic hydrothermal reactor and kept at a constant temperature for $3 \mathrm{~h}$; then the solution was cooled down to room temperature. By filtrating three times (filter with $0.22 \mu \mathrm{m}$ hole) and dialysis (1000 D) for $18 \mathrm{~h}$, a pure N-GQD solution was obtained. After freeze drying, solid-phase N-GQDs were obtained and stored in a refrigerator at $4{ }^{\circ} \mathrm{C}$ for later use.
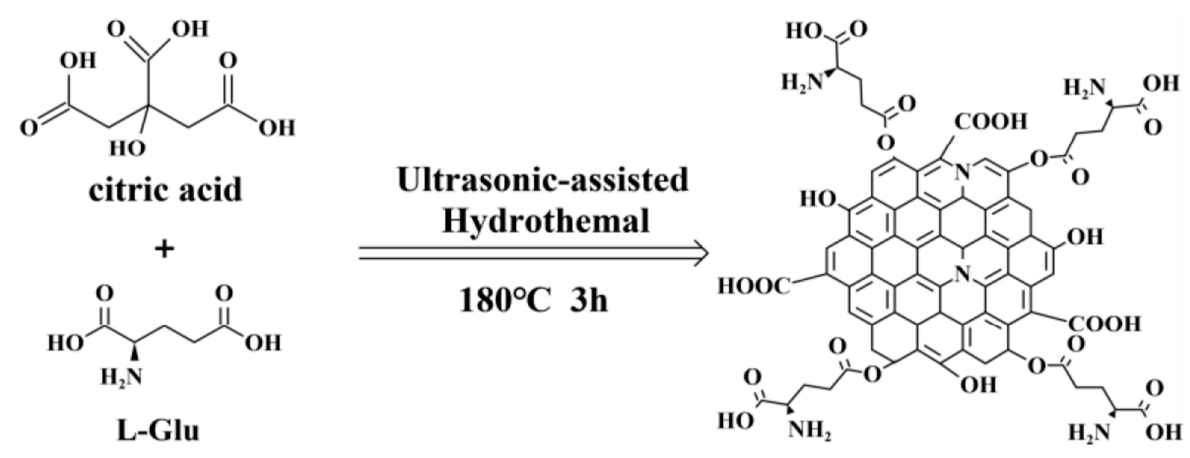

Scheme 1. Schematic diagram of the formation of N-GQDs by ultrasonic-assisted hydrothermal method.

\section{Results and Discussion}

\subsection{Morphology and Structure of the N-GQDs}

The morphology and structure of the N-GQDs were characterized in detail using TEM, HRTEM, AFM and XRD. Figure 1 presents the experimental results; TEM (Figure 1A) shows that the N-GQDs have a good dispersity, with most N-GQDs being circular nanosheets; the statistical calculation for more than 100 N-GQDs indicated that the average diameter of the N-GQDs was about $2.65 \mathrm{~nm}$ (Figure 1B); the clear and regular lattice fringes in the HRTEM image (Figure 1C) indicate that the interplanar spacing of the N-GQDs was $0.213 \mathrm{~nm}$, which is equivalent to graphite carbon [36]; AFM images (Figure 1D,E) indicate that the heights 
of the N-GQDs were in the range of 1.5-4.5 nm, implying that the N-GQDs contained 4-12 layers of graphene [37]; the XRD pattern of the N-GQDs indicates a wide diffraction peak at $2 \theta=21.06^{\circ}$, corresponding to the (002) crystal facet of graphene [38]. According to the Bragg equation $2 \mathrm{~d} \operatorname{Sin} \theta=\lambda$ [39], the layer spacing was about $d=0.36 \mathrm{~nm}$, which is larger than that of graphite $(0.335 \mathrm{~nm})$ [40]; the main reasons for this are the nitrogen doping of the GQDs and the oxygen-containing functional groups at the edges of the GQDs [41].
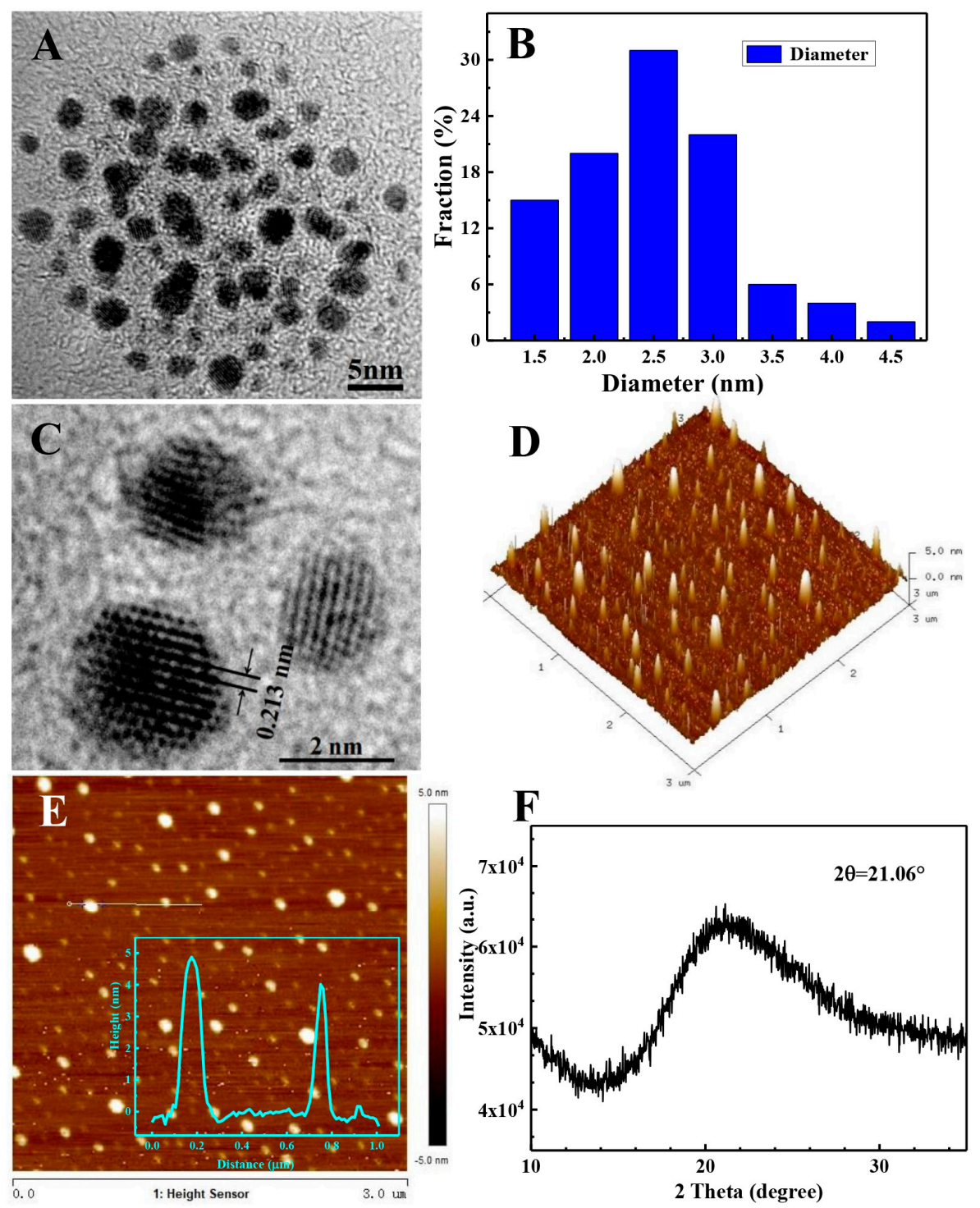

Figure 1. (A) TEM, (B) size distribution, (C) HRTEM, (D,E) AFM, and (F) XRD pattern of the N-GQDs.

\subsection{Surface Chemistry of the N-GQDs}

The surface chemical architectures of the N-GQDs were detected using FTIR (Figure 2) and XPS (Figure 3). For comparison, the FTIR spectra of pure CA and L-Glu were also measured (Figure 2a,b). The FTIR spectrum of CA shows O-H stretching $\left(3490-3280 \mathrm{~cm}^{-1}\right), \mathrm{C}=\mathrm{O}$ stretching (1750 and $\left.1710 \mathrm{~cm}^{-1}\right),-\mathrm{CH}_{2}$ - scissor vibration $\left(1430 \mathrm{~cm}^{-1}\right),-\mathrm{CH}_{2}-$ oscillation out of plane $\left(1390 \mathrm{~cm}^{-1}\right)$, in-plane deformation vibration of $\mathrm{C}-\mathrm{OH}$ bond $\left(1180-1290 \mathrm{~cm}^{-1}\right.$ and $\left.1310-1360 \mathrm{~cm}^{-1}\right)$, twisting vibration of $-\mathrm{CH}_{2}-\left(1220-1240 \mathrm{~cm}^{-1}\right), \mathrm{C}-\mathrm{O}$ stretching (1080-1140 $\left.\mathrm{cm}^{-1}\right)$ and C-C stretching $\left(1050 \mathrm{~cm}^{-1}\right)$ peaks (Figure 2a) [42,43]. The FTIR of L-Glu (Figure $2 \mathrm{~b}$ ) exhibits $\mathrm{O}-\mathrm{H}$ and $\mathrm{N}-\mathrm{H}$ stretching $\left(2780-3600 \mathrm{~cm}^{-1}\right),-\mathrm{C}-\mathrm{H}$ stretching $\left(2650-2740 \mathrm{~cm}^{-1}\right)$, carboxylic acid of $\mathrm{C}=\mathrm{O}$ stretching $\left(1740\right.$ and $\left.1640 \mathrm{~cm}^{-1}\right), \mathrm{N}-\mathrm{H}$ out-ofplane bending vibration $\left(1510 \mathrm{~cm}^{-1}\right), \mathrm{C}-\mathrm{N}$ stretching $\left(1420 \mathrm{~cm}^{-1}\right),-\mathrm{CH}_{2}-$ oscillation out of plane $\left(1360 \mathrm{~cm}^{-1}\right)$, twisting vibration of $-\mathrm{CH}_{2}-\left(1250-1310 \mathrm{~cm}^{-1}\right)$, in-plane deformation 
vibration of $\mathrm{C}-\mathrm{OH}$ bond $\left(1130 \mathrm{~cm}^{-1}\right.$ and $\left.1230 \mathrm{~cm}^{-1}\right), \mathrm{C}-\mathrm{O}$ stretching $\left(1080-1130 \mathrm{~cm}^{-1}\right)$ and $C-C$ stretching $\left(1050 \mathrm{~cm}^{-1}\right)$ peaks [44]. By contrast, the FTIR of N-GQDs shows the intensification of $\mathrm{O}-\mathrm{H}$ and $\mathrm{N}-\mathrm{H}$ stretching, $\mathrm{C}-\mathrm{O}$ stretching, deformation vibration of $\mathrm{C}-\mathrm{OH}$ bond and $\mathrm{C}=\mathrm{O}$ stretching, demonstrating that the oxygen content in the N-GQDs was increased, and that the number of oxygen-containing functional groups was also increased. Notably, the formation of $\mathrm{C}=\mathrm{C}$ stretching $\left(1650 \mathrm{~cm}^{-1}\right)$ and the intensification of $-\mathrm{C}-\mathrm{H}$ stretching and $\mathrm{C}-\mathrm{C}$ stretching peaks in N-GQDs, indicating that the formation of $\mathrm{sp}^{2}$ (graphitic) or $\mathrm{sp}^{3}$ (amorphous) carbon structures [45]. In addition, the distinct characteristic peak at $1220 \mathrm{~cm}^{-1}$ belongs to the stretching vibration of the $\mathrm{C}-\mathrm{O}-\mathrm{C}$ bond [46], it was presumably formed by decarboxylation of the $\mathrm{CA}$ as conjugating to GQDs. The presence of the $\mathrm{N}-\mathrm{H}$ bond and the $\mathrm{C}-\mathrm{N}$ bond on the N-GQDs also show L-Glu conjugated to the GQDs. Our fabrication method demonstrates that GQDs can be amino-functionalized during the synthesis process. Comparison to the two-step approach (first fabrication of GQDs, then amino-modification), the one-step method is easier and saves time. The amino-functionalized GQDs benefit from their biocompatibility; the groups of hydroxyl, carboxyl, carbonyl, and amino in the N-GQDs indicate its good hydrophilicity and stability in solution [47].

The XPS characterization was carried out in order to further analyze the elemental compositions and chemical bonds of the obtained N-GQDs. As illustrated in Figure 3A, the full scan spectrum of XPS exhibits three obvious peaks at 545.0, 402.2 and $298.1 \mathrm{eV}$, revealing the presence of $\mathrm{O} 1 \mathrm{~s}, \mathrm{~N} 1 \mathrm{~s}$ and $\mathrm{C} 1 \mathrm{~s}$, respectively. Quantitative determination of the XPS spectrum shows that the as-prepared N-GQDs consisted of $36.42 \% \mathrm{O}, 3.57 \% \mathrm{~N}$ and $60.01 \% \mathrm{C}$, indicating the successful doping of nitrogen into the GQDs. The $\mathrm{C}$ to $\mathrm{O}$ atomic ratio for the N-GQDs was about 1.65, which is slightly higher than that reported in [28] (1.51), demonstrating that the N-GQDs have a low oxidation level [48]. The $\mathrm{N}$ to $\mathrm{C}$ atomic ratio was calculated to be 0.06 , which is as same as that reported in [28], but remarkably higher than that of the N-GQDs prepared using the electrochemical method $(0.04)[49,50]$. The deconvolution of the high-resolution XPS spectra of $\mathrm{C} 1 \mathrm{~s}$ (Figure 3B) reveals five main peaks, confirming the presence of $\mathrm{C}=\mathrm{C} / \mathrm{C}-\mathrm{C}(284.5 \mathrm{eV}), \mathrm{C}-\mathrm{N}(285.2 \mathrm{eV}), \mathrm{C}-\mathrm{OH}(286.4 \mathrm{eV})$, $\mathrm{C}=\mathrm{O}(287.3 \mathrm{eV})$, and $\mathrm{O}-\mathrm{C}=\mathrm{O}(288.9 \mathrm{eV})$ bonds [51], indicating that the as-prepared N-GQDs are rich in hydrophilic groups, such as hydroxyl, carboxyl, and carbonyl groups on the surfaces of N-GQDs, which is consistent with the result of FTIR. The deconvolution of the N1s spectrum (Figure 3C) shows three peaks at 399.9, 400.5, and $401.7 \mathrm{eV}$. The fitting results coincide well with the experimental results; the three peaks are attributed to the pyridinic $\mathrm{N}$, pyrrolic $\mathrm{N}$ and graphitic $\mathrm{N}$ respectively [52], confirming again that nitrogen was partly doped into the GQDs. The fitted peaks at 532.1, 532.8 and $533.6 \mathrm{eV}$ of O1s XPS spectrum shown in Figure 3D can be assigned to the three components $\mathrm{C}=\mathrm{O}, \mathrm{C}-\mathrm{O}$, and $\mathrm{C}-\mathrm{OH}$ [53], respectively, which is in agreement with the XPS spectrum of C1s.

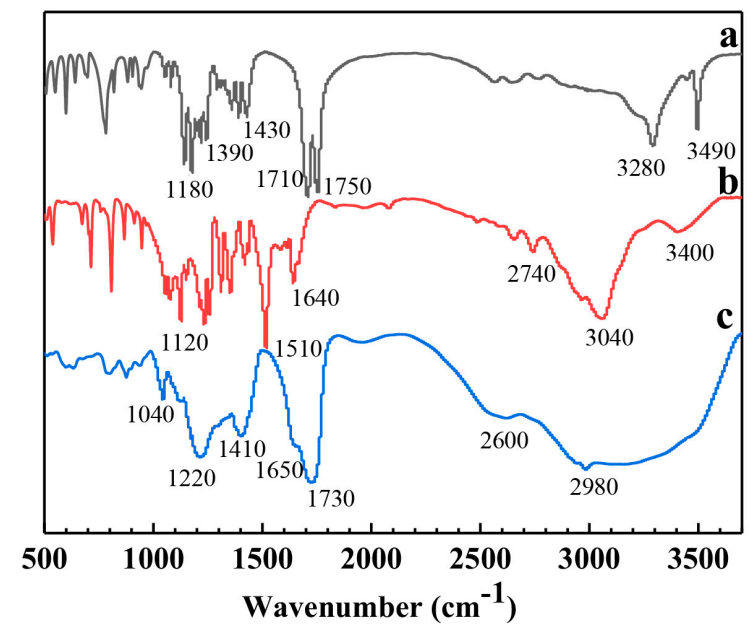

Figure 2. FTIR spectra of (a) CA, (b) L-Glutamic, and (c) N-GQDs. 

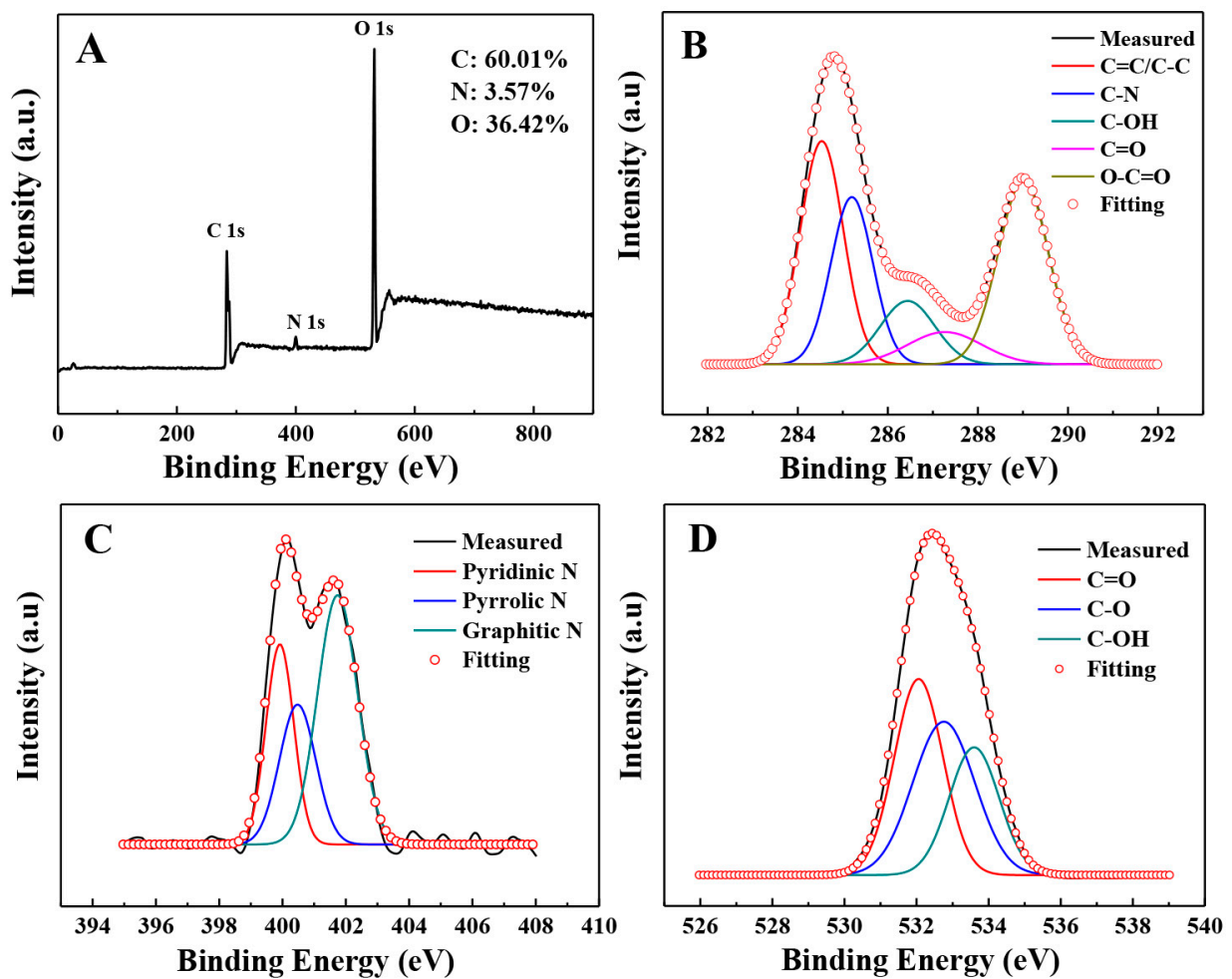

Figure 3. (A) Full scan XPS spectrum of the N-GQDs, and high solution XPS spectra of (B) C1s, (C) N1s, and (D) O1s.

\subsection{Optical Properties}

The UV-Vis absorption spectra (Figure 4A, Abs) of the N-GQDs aqueous solution shows an obvious absorption peak at $230 \mathrm{~nm}$, which can be attributed to the $\pi \rightarrow \pi^{*}$ electronic transition of the aromatic sp ${ }^{2}$ domains [54]; the absorption peak near $300 \mathrm{~nm}$ from the $n \rightarrow \pi^{*}$ transition of the heteroatom double bond in GQDs is very weak, indicating the existence of functional groups containing lone pairs of electrons (such as carboxyl groups, etc.) [55]; the excitation (Figure 4A, Ex) and emission (Figure 4A, Em) spectra exhibit good mirror symmetry; the N-GQDs emitted a very bright blue fluorescence that could be observed by naked eye (Figure $4 \mathrm{~A}$, inset). When the excitation wavelengths were changed from $300 \mathrm{~nm}$ to $500 \mathrm{~nm}$ (Figure $4 \mathrm{~B}$ ), the emission peaks of N-CQDs shifted from $430 \mathrm{~nm}$ to $548 \mathrm{~nm}$ (Figure 4C,D), and the maximum intensity was obtained at the excitation of $370 \mathrm{~nm}$ (Figure 4B); when the excitation was in the range of 300-370 nm, the emission peaks were almost invariable $(\sim 47 \mathrm{~nm})$, indicating that the emission spectra are excitation independent; thus, from the emission was mainly produced by the carbon core $\left(\mathrm{sp}^{2}\right.$ domain) of the N-GQDs (band I) [56]. Meanwhile, with excitation in the range from 380 to $500 \mathrm{~nm}$, the emission peaks increased with the excitation wavelength, implying that the emission originated from the transitions related to the surface states (hybridization of the carbon backbone and connected chemical groups) (band II). In [55], excitation-dependent emissions were associated with both the $n-\pi^{*}$ transition of the N/O surface groups and the $\pi-\pi^{*}$ charge transfer between the carbon core and the edge of the GQDs. The full width at half maximum (FWHM) of the strongest emission spectrum was only $87 \mathrm{~nm}$. Compared with the reported GQDs synthesized with CA [57], our N-GQDs indicate a narrow emission range; the main reason for this is that L-Glu-functionalized GQDs decrease the surface defects. The QY of the N-GQDs was determined to be $54 \%$ (calculation data is shown in Table S1 of Supporting Information). This relatively high QY might be due to the low oxygen content [58], $\mathrm{N}$ doping and the protection of the L-Glu as the surface passivation agent. The high QY and narrow FWHM imply that the N-GQDs could be used for imaging or as fluorescent sensors. 



Figure 4. (A) The absorption, excitation and emission spectra of N-GQDs. Inset: from left to right are the N-GQDs aqueous solutions under ambient light and UV excitation (irradiated from an optical fiber), respectively; (B) the PL spectra of N-GQDs under excited different excitation wavelengths; (C) the peak positions and (D) the maximum intensities of the PL spectra varying with the excitation wavelengths in (B).

The photo-stability of the N-GQDs is easily influenced by photo-bleaching, $\mathrm{pH}$ value, temperature and preservation time. For practical applications, the photo-stability is very important. Here we probed this question in detail. The results show that the N-GQDs exhibited excellent photo-stability. Under continuous excitation (at $370 \mathrm{~nm}$ ) for $50 \mathrm{~min}$, the fluorescence intensity remained invariable, indicating the N-GQDs have superior photobleaching resistance (Figure 5A). Compared with previously reported N-GQDs [47,59], our $\mathrm{N}$-GQDs show excellent photo-bleaching resistance. For comparison, the traditional organic dye Propidium iodide (PI) was also continuously irradiated for $50 \mathrm{~min}$ (Figure 5A, blue line); after irradiation for $10 \mathrm{~min}$ and $50 \mathrm{~min}$, the intensity of PI decreased by $19 \%$ and $25 \%$, respectively. The above results show that the prepared N-GQDs not only exhibit high QY, but also excellent photo-bleaching resistance. It can be inferred that the N-GQDs should be an excellent candidate for bioimaging.

The fluorescence intensities of the N-GQDs varying with $\mathrm{pH}$ value in the range of 2-9 (adjusted by $\mathrm{HCl}$ and $\mathrm{NaOH}$ ) are shown in Figure 5B. Because the intensities did not show any obvious change with $\mathrm{pH}$ values in the range of 3-8, it was concluded that the as-prepared N-GQDs exhibit good stability under acid and neutral $\mathrm{pH}$ environments, and thus the protonation or deprotonation of the N-GQDs is also very weak [60-62]. Compared with the results reported in [63], the as-prepared N-GQDs can be used in a wide range of $\mathrm{pH}$ environments. Thus, the N-GQDs have good prospects for the fluorescence imaging of cells and other living organisms. 

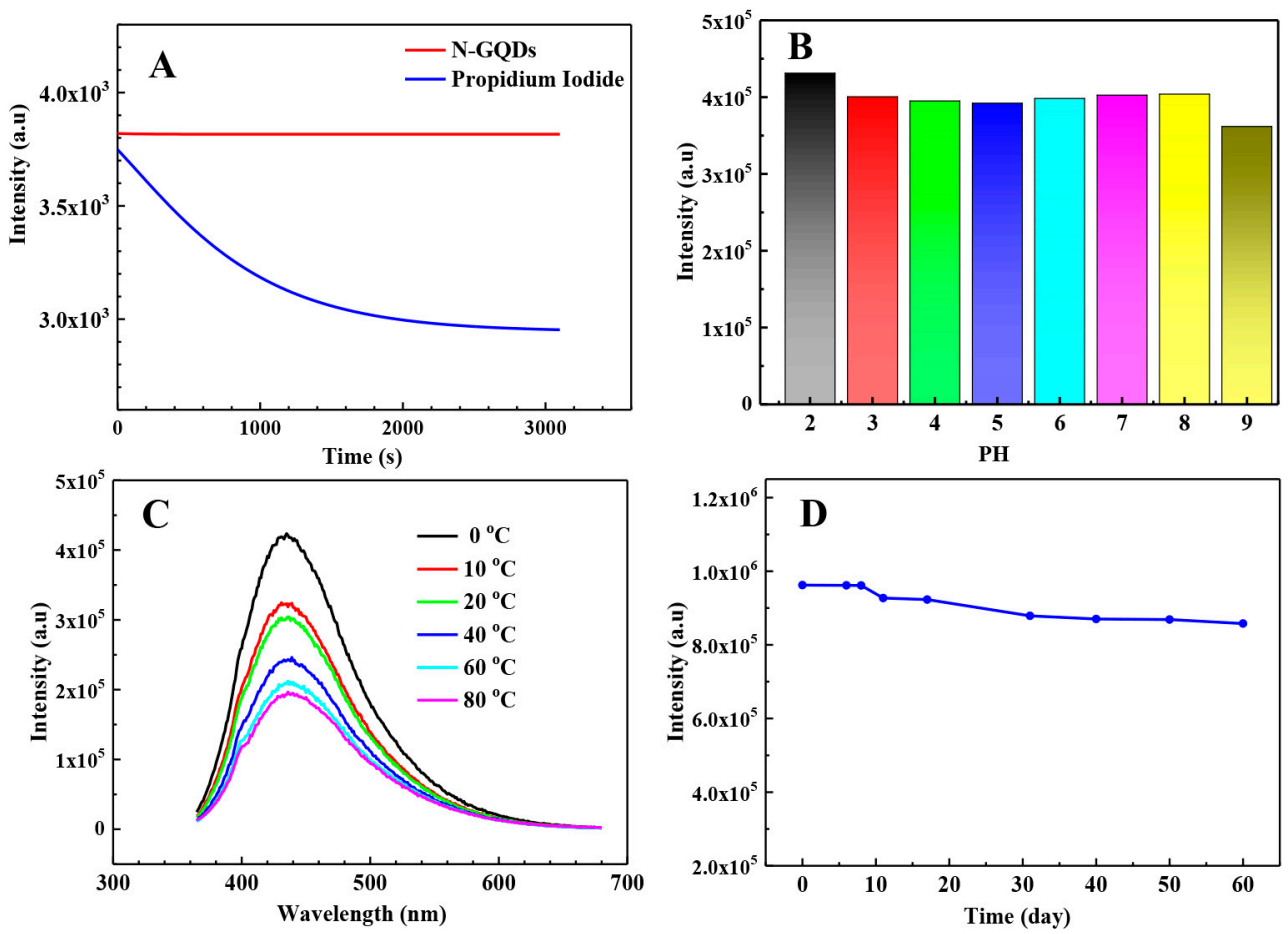

Figure 5. The photo-stability of the N-GQDs. (A) The photo-bleaching resistance of the N-GQDs and the traditional dye of propidium iodide; the PL peak intensities varying with (B) $\mathrm{pH}$ and (C) temperature; and (D) the PL peak intensities over 2 months.

The thermal stability of N-GQDS is also an important parameter for their application. The emission spectra of the N-GQDs were measured in the range of $0-80^{\circ} \mathrm{C}$. As shown in Figure 5C, the peak positions of the emission spectra were close to $447 \mathrm{~nm}$, but the intensities decrease with increasing temperature, indicating that the thermal stability of the $\mathrm{N}$-GQDS is not so good; the peak intensity at $40{ }^{\circ} \mathrm{C}$ is $80 \%$ of that at $20^{\circ} \mathrm{C}$.

Whether the N-GQDs can be preserved for a long time is also a significant index for their application. As shown in Figure 5D, the emission spectra of the N-GQDs were measured over a $60 \mathrm{~d}$ storage period. After storage at $4{ }^{\circ} \mathrm{C}$ for $8,11,17,31,40$ and 60 days, the peak intensities at $447 \mathrm{~nm}$ of the emission spectra were $99.66 \%, 96.13 \%, 95.68 \%, 91.10 \%$, $90.20 \%$ and $88.92 \%$ of the as-prepared N-GQDs, indicating that the N-GQDs can be stably preserved for at least 40 days.

The above results show that the ultrasonic hydrothermal approach is facile for obtaining N-doped GQDs with excellent photo-physical properties and stability.

\subsection{Mechanism of Photoluminescence}

To further investigate the emission mechanism of the N-GQDs, the fluorescence lifetime of the N-GQDs was measured using the time-correlated single photon counting (TCSPC) technique. The fluorescence lifetime of the N-GQDs was detected using an Edinburgh F900 time-resolved fluorescence spectrometer with an LED $(370 \mathrm{~nm})$. The monitor emission wavelength of the N-GQDs is $447 \mathrm{~nm}$. The decay curve could be well fitted as a three-exponential function, and contains two fast decays ( $0.62 \mathrm{~ns}$ and $2.38 \mathrm{~ns})$ and one slow decay (16.65 ns), which implies that the N-GQDs have two emission centers; the slow component lifetime is suggested to be related to the surface states in N-GQDs, while the quick lifetimes are related to the carbon core of the graphene structure in the $\mathrm{N}$-GQDs [64]. The decay lifetimes are in good agreement with carbon-based quantum dots grown using different methods, such as chemical exfoliation [65] and the electrochemical method [66]. The average exciton lifetime $\left(\tau_{a v}\right)$ is $2.653 \mathrm{~ns}$. Additionally, the radiative $\left(\kappa_{r}\right)$ 
and nonradiative decay rate constants $\left(\kappa_{n r}\right)$ can be obtained on the basis of the measured QY $(\varphi)$ and average PL lifetime $\left(\tau_{a v}\right)$ using the following equations [67]:

$$
\begin{gathered}
\kappa_{r}=\Phi / \tau_{a v} . \\
\kappa_{r}+\kappa_{n r}=1 / \tau_{a v}
\end{gathered}
$$

The results are $\kappa_{\mathrm{r}}=2.04 \times 10^{8} \mathrm{~s}^{-1}$ and $\kappa_{n r}=1.73 \times 10^{8} \mathrm{~s}^{-1}$.

Since both the source (CA and L-Glu) and the solvent (DI water) exhibit extremely weak UV absorption and emission, there should be a fluorescence emission originating from the N-GQDs. The fluorescence emission of the L-Glu-passivated N-GQDs can be attributed to the $\pi$ electron transition of $C=C$ in the core of N-GQD, which consists of a graphene structure and the surface groups of the N-GQDs [68]. As demonstrated above, our N-GQDs consist of a carbon core, as well as $\mathrm{O}-, \mathrm{H}-$-, and $\mathrm{N}$-containing functional groups on the surfaces of the N-GQDs. On the basis of the FTIR and XPS results, it can be seen that there are different kinds of functional groups $(\mathrm{C}-\mathrm{OH}, \mathrm{C}=\mathrm{O}, \mathrm{C}-\mathrm{O}-\mathrm{C}, \mathrm{C}-\mathrm{H}, \mathrm{C}-\mathrm{N}$, and $\mathrm{N}-\mathrm{H})$ present on the surfaces of the N-GQDs; "surface states" are formed via the hybridization of the carbon backbone and the connected chemical groups, and the corresponding energy levels are situated between the $\pi$ and $\pi^{*}$ states of $\mathrm{sp}^{2} \mathrm{C}$ [69]; therefore, the distributed surface states are a reasonable explanation for the difference in chemical bonding in the GQDs. The absorption and emission transitions of the N-GQDs and their energy levels are shown schematically in Figure 6C. In Figure 4C, the excitation-independent emission corresponds to excitation wavelengths of less than $370 \mathrm{~nm}$; therefore, the energy difference between $\pi$ and $\mathrm{n}$ can be estimated on the basis of the intrinsic excitation at $285 \mathrm{~nm}(4.35 \mathrm{eV})$ and $370 \mathrm{~nm}(3.35 \mathrm{eV})$ (Figure $6 \mathrm{~A})$, which is about $1.0 \mathrm{eV}$. The PL spectra from the carbon core of the graphene structure in the GQDs does not vary with excitation wavelength [56]; therefore, band I (in Figure 4B-D) is excitation independent. The surface states have various energy levels [70]; when a certain excitation wavelength illuminates the N-GQDs, a surface state emission dominates the emission; as the excitation wavelength changes, another corresponding surface state emission may become dominant. In addition to this, the electrons excited to $\pi^{*}$ may relax into surface states, emitting via radiative combination or not emitting via nonradiative combination. Thus, the excitation-dependent PL of the GQDs (band II in Figure 4B-D) is mainly a result of the surface states.

\subsection{Fluorescence Cell Imaging with the N-GQDs}

Most GQDs can be used for biomedical imaging because of their low cytotoxicity, excellent biocompatibility, high fluorescent QY, and excellent photo-bleaching resistance [71,72]. Herein, we used N-GQDs as fluorescent probes for the imaging of BV2 cells. Briefly, BV2 cells were placed on the confocal plate. The cells were cultured in Dulbecco's modified Eagle medium (DMEM) containing 1\% penicillin-streptomycin and $10 \%$ fetal bovine serum (FBS) in an incubator with $5 \% \mathrm{CO}_{2}$ and $95 \%$ humidity at $37^{\circ} \mathrm{C}$. The culture solution was changed every other day. When the cell density reached about $80 \%\left(\sim 5 \times 10^{4}\right.$ cells $\left./ \mathrm{mL}\right)$, $200 \mu \mathrm{g} / \mathrm{mL}$ N-GQDS was added to the cell medium and cultured at $37{ }^{\circ} \mathrm{C}$ and $5 \% \mathrm{CO}_{2}$ for $1 \mathrm{~h}$. Finally, the BV2 cells were washed three times using PBS buffer (pH 7.4), and the morphology of the BV2 cells was observed and imaged using confocal LSM. The cells displayed enhanced blue ( $405 \mathrm{~nm}$ laser excitation) or green ( $488 \mathrm{~nm}$ laser excitation) fluorescence around their nucleus (Figure 7), indicating that the N-GQDs were able to label the cell membrane and the cytoplasm. Studies have shown that N-GQDs are likely to enter the cytoplasm, which can be attributed to the smaller amount of carboxyl on the surface of N-GQDs [68,73-76]. The abundant surface functional groups in N-GQDs (carboxyl, carbonyl, hydroxyl, and amino) ensure that they adhere easily to the negatively charged cell membrane [77-79], thus achieving effective uptake by cells. By comparing the bright field with the dark field images, the number of stained cells accounted for more than $90 \%$, demonstrating the low cytotoxicity and good biocompatibility of the N-GQDs. 

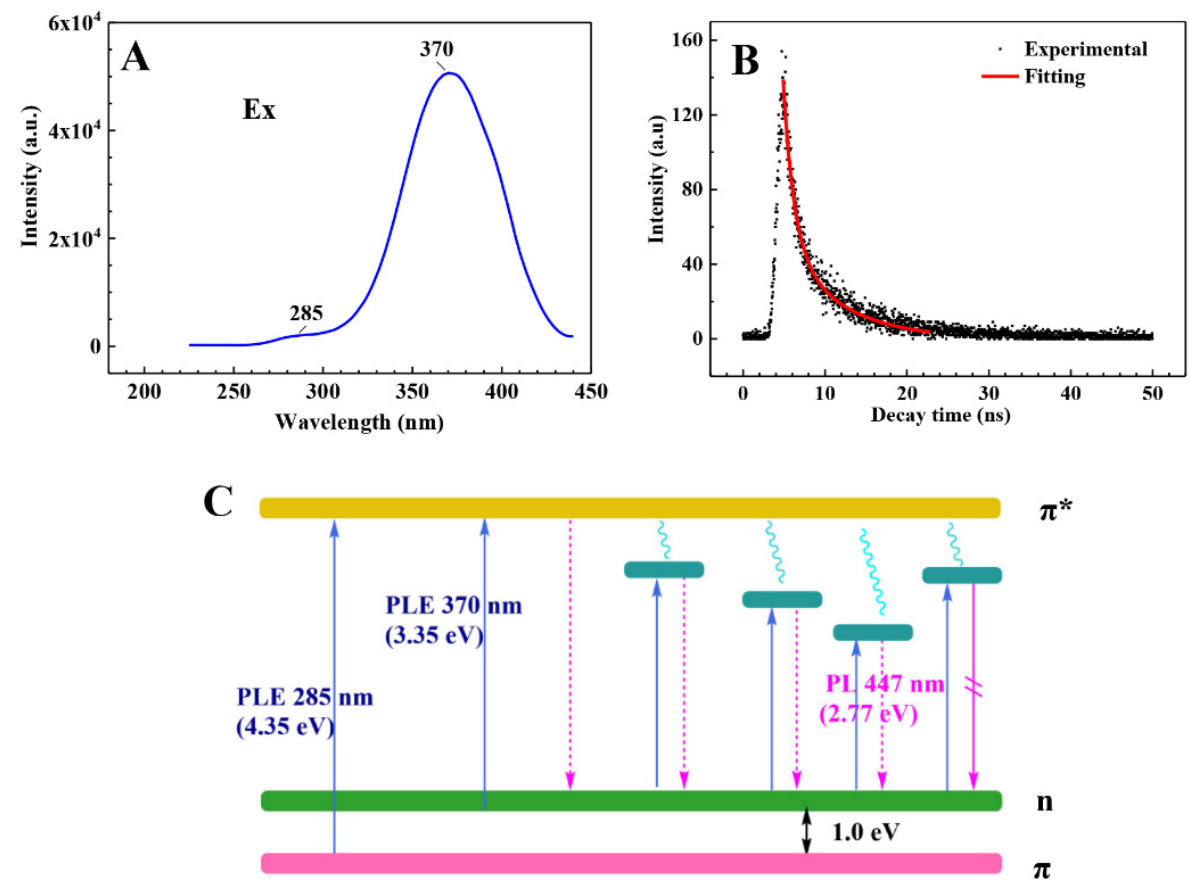

Figure 6. The photoluminescence mechanism of the N-GQDs: (A) the excitation spectrum obtained under the monitor emission wavelength at $447 \mathrm{~nm}$ and the excitation in the range of 200-430 nm; (B) the fluorescence lifetime of the N-GQDs; and (C) the schematic energy level of the N-GQDs.

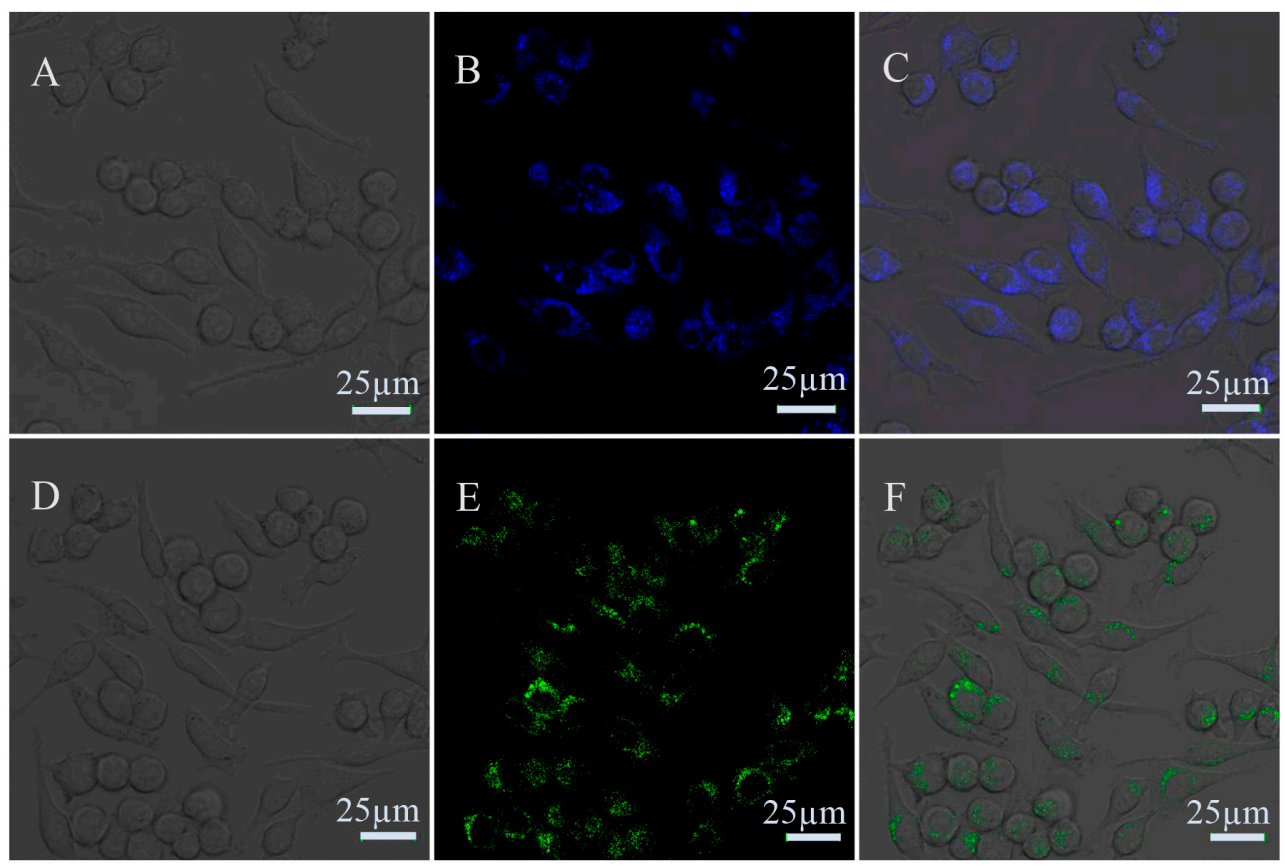

Figure 7. Laser scanning confocal fluorescence microscopy images of BV-2 cells: $(\mathbf{A}, \mathbf{D})$ the cells imaged under bright field, (B) $405 \mathrm{~nm}$ laser excitation, (C) overlay of (A,B), (E) $488 \mathrm{~nm}$ laser excitation, and $(\mathbf{F})$ overlay of $(\mathbf{D}, \mathbf{E})$.

\section{Conclusions}

The ultrasonic-assisted hydrothermal method is a facile method for obtaining bright blue fluorescent N-doped GQDs with CA as a precursor and L-Glu for N doping. The morphology, size, structure, surface chemistry, optical properties, and stability subject to photo-bleaching, temperature, $\mathrm{pH}$ and preservation period of the N-GQDs were investigated in detail. The results showed that the N-GQDs possess sizes in the range of 
3-6 nm, with an average size of $2.65 \mathrm{~nm}$, containing $36.42 \% \mathrm{O}, 3.57 \% \mathrm{~N}$ and $60.01 \% \mathrm{O}$, and possessing good water solubility, outstanding optical properties, excellent photo-bleaching resistance and stability, and good biocompatibility. The PL spectra of the N-GQDs are excitation dependent with excitation in the range of $300-370 \mathrm{~nm}$ and excitation independent with excitation in the range of $380-500 \mathrm{~nm}$ for core and surface state emissions. The QY reaches up to $54 \%$. At room temperature and in the $\mathrm{pH}$ range of 3-8, the fluorescence of the N-GQDs is almost invariable. The N-GQDs can be stably preserved for at least 40 days. The average decay lifetime of the N-GQDs was measured to be $2.653 \mathrm{~ns}$. The calculated radiative and nonradiative decay rate constants were $2.04 \times 10^{8} \mathrm{~s}^{-1}$ and $1.73 \times 10^{8} \mathrm{~s}^{-1}$, respectively. The PL mechanism was explained qualitatively. The N-GQDs were used for BV2 cell imaging and showed good results, implying great potential applications for bioimaging or biomarking.

Supplementary Materials: The following are available online at https://www.mdpi.com/article/ 10.3390/nano11112798/s1, Figure S1: The absorption and PL spectra of N-GQDs obtained under different conditions, Table S1: Quantum yields of N-GQDs under different reaction conditions.

Author Contributions: H.W.: investigation, data curation, formal analysis, and writing-original draft; C.Q.: investigation and data curation; A.Y.: conceptualization, methodology, investigation, project administration, resources, supervision, writing and editing; X.W.: cell cultivation and cell imaging; J.X.: resources, cell cultivation and cell imaging. All authors have read and agreed to the published version of the manuscript.

Funding: This research was funded by National Natural Science Foundation of China, Grant No. 41877499.

Institutional Review Board Statement: Not applicable.

Informed Consent Statement: Not applicable.

Data Availability Statement: The data used to support the findings of this study are available from the corresponding author upon request.

Acknowledgments: This research was supported by the National Natural Science Foundation of China (Grant No. 41877499).

Conflicts of Interest: The authors declare that they have no known competing financial interests or personal relationships that could have appeared to influence the work reported in this paper.

\section{References}

1. Geim, A.K.; Novoselov, K.S. The rise of graphene. Nat. Mater. 2009, 6, 11-19.

2. Liu, S.H.; Liu, Z.C.; Li, Q.F.; Xia, H.J.; Yang, W.J.; Wang, R.X.; Li, Y.X.; Zhao, H.; Tian, B.S. Facile synthesis of carbon dots from wheat straw for colorimetric and fluorescent detection of fluoride and cellular imaging. Spectrochim. Acta A Mol. Biomol. Spectrosc. 2021, 246, 118964. [CrossRef]

3. Liu, H.; Hao, C.; Nan, Z.; Qu, H.; Zhang, X.; Zhang, Z.; Sun, R. Fabrication of graphene oxide and sliver nanoparticle hybrids for fluorescence quenching of DNA labeled by methylene blue. Spectrochim. Acta A Mol. Biomol. Spectrosc. 2020, $243,118802$. [CrossRef]

4. Kuila, T.; Bose, S.; Mishra, A.K.; Khanra, P.; Kim, N.H.; Lee, J.H. Chemical functionalization of graphene and its applications. Prog. Mater. Sci. 2012, 57, 1061-1105. [CrossRef]

5. Tang, Q.; Zhen, Z. Graphene-analogous low-dimensional materials. Prog. Mater. Sci. 2013, 58, 1244-1315. [CrossRef]

6. Xu, J.; Qing, T.; Jiang, Z.; Zhang, P.; Feng, B. Graphene oxide-regulated low-background aptasensor for the "turn on" detection of tetracycline. Spectrochim. Acta A Mol. Biomol. Spectrosc. 2021, 260, 119898. [CrossRef] [PubMed]

7. Song, Y.; Qu, K.; Zhao, C.; Ren, J.; Qu, X. Graphene Oxide: Intrinsic Peroxidase Catalytic Activity and Its Application to Glucose Detection. Adv. Mater. 2010, 22, 2206-2210. [CrossRef] [PubMed]

8. Zheng, X.T.; Than, A.; Ananthanaraya, A.; Kim, D.H.; Chen, P. Graphene quantum dots as universal fluorophores and their use in revealing regulated trafficking of insulin receptors in adipocytes. ACS Nano 2013, 7, 6278-6286. [CrossRef] [PubMed]

9. Sun, H.; Wu, L.; Gao, N.; Ren, J.; Qu, X. Improvement of Photoluminescence of Graphene Quantum Dots with a Biocompatible Photochemical Reduction Pathway and Its Bioimaging Application. ACS Appl. Mater. Interfaces 2013, 5, 1174-1179. [CrossRef] [PubMed]

10. Kortel, M.; Mansuriya, B.D.; Vargas Santana, N.; Altintas, Z. Graphene Quantum Dots as Flourishing Nanomaterials for Bio-Imaging, Therapy Development, and Micro-Supercapacitors. Micromachines 2020, 11, 866. [CrossRef] [PubMed] 
11. Wang, L.H.; Bu, Y.M.; Liu, Y.; Yao, Y.P.; Yang, Z.F.; Chen, P.; Tang, D.J.; Meng, L.; Cui, B. A Strategy for Microwave-Controlled Release of Anticancer Drugs: (Fe3O4/nGO) @mSiO2/GQDs Nanocomposite Carrier Jointly Enhanced by nGO and GQDs. Nano 2020, 15, 2050071. [CrossRef]

12. Li, R.; Cui, F.; Zhu, H.; Sun, X.; Li, Z. Electrochemical sensor for detection of cancer cell based on folic acid and octadecylaminefunctionalized graphene aerogel microspheres. Biosens. Bioelectron. 2018, 119, 156-162.

13. Xu, H.; Zhou, S.; Xiao, L.; Wang, H.; Li, S.; Yuan, Q. Fabrication of a nitrogen-doped graphene quantum dot from MOF-derived porous carbon and its application for highly selective fluorescence detection of Fe3+. J. Mater. Chem. C 2015, 3, 291-297. [CrossRef]

14. Shehab, M.; Ebrahim, S.; Soliman, M.M. Graphene quantum dots prepared from glucose as optical sensor for glucose. J. Lumin. 2017, 184, 110-116. [CrossRef]

15. Pang, P.; Yan, F.; Li, H.; Li, H.; Zhang, Y.; Wang, H.; Wu, Z.; Yang, W. Graphene quantum dots and Nafion composite as an ultrasensitive electrochemical sensor for the detection of dopamine. Anal. Methods 2016, 8, 4912-4918. [CrossRef]

16. Ghosh, D.; Sarkar, K.; Devi, P.; Kim, K.H.; Kumar, P. Current and future perspectives of carbon and graphene quantum dots: From synthesis to strategy for building optoelectronic and energy devices. Renew. Sust. Energ. Rev. 2021, 135, 110391. [CrossRef]

17. Gupta, V.; Chaudhary, N.; Srivastava, R.; Sharma, G.D.; Bhardwaj, R.; Chand, S. Luminscent graphene quantum dots for organic photovoltaic devices. J. Am. Chem. Soc. 2011, 133, 9960-9963. [CrossRef] [PubMed]

18. Jin, Z.; Owour, P.; Lei, S.; Ge, L. Graphene, graphene quantum dots and their applications in optoelectronics. Curr. Opin. Colloid. Interface Sci. 2015, 20, 439-453. [CrossRef]

19. Son, D.I.; Kwon, B.W.; Park, D.H.; Seo, W.S.; Yi, Y.; Angadi, B.; Lee, C.L.; Choi, W.K. Emissive ZnO-graphene quantum dots for white-light-emitting diodes. Nat. Nanotechnol. 2012, 7, 465-471. [CrossRef]

20. Liu, J.; Liu, Y.; Liu, N.; Han, Y.; Zhang, X.; Huang, H.; Lifshitz, Y.; Lee, S.-T.; Zhong, J.; Kang, Z. Metal-free efficient photocatalyst for stable visible water splitting via a two-electron pathway. Science 2015, 347, 970-974. [CrossRef]

21. Yang, Z.; Xu, M.; Liu, Y.; He, F.; Gao, F.; Su, Y.; Wei, H.; Zhang, Y. Nitrogen-doped, carbon-rich, highly photoluminescent carbon dots from ammonium citrate. Nanoscale 2014, 6, 1890-1895. [CrossRef]

22. Pan, D.; Zhang, J.; Li, Z.; Wu, M. Hydrothermal route for cutting graphene sheets into blue-luminescent graphene quantum dots. Adv. Mater. 2010, 22, 734-738. [CrossRef]

23. Sangam, S.; Gupta, A.; Shakeel, A.; Bhattacharya, R.; Sharma, A.K.; Suhag, D.; Chakrabarti, S.; Garg, S.K.; Chattopadhyay, S.; Basu, B.; et al. Sustainable synthesis of single crystalline sulphur-doped graphene quantum dots for bioimaging and beyond. Green Chem. 2018, 20, 4245-4259. [CrossRef]

24. Dong, Y.; Shao, J.; Chen, C.; Li, H.; Wang, R.; Chi, Y.; Lin, X.; Chen, G. Blue luminescent graphene quantum dots and graphene oxide prepared by tuning the carbonization degree of citric acid. Carbon 2012, 50, 4738-4743. [CrossRef]

25. Kaewanan, P.; Sricharoen, P.; Limchoowong, N.; Sripakdee, T.; Nuengmatcha, P.; Chanthai, S. A fluorescence switching sensor based on graphene quantum dots decorated with $\mathrm{Hg} 2+$ and hydrolyzed thioacetamide for highly Ag+-sensitive and selective detection. RSC Adv. 2017, 7, 48058-48067. [CrossRef]

26. Du, F.; Jin, X.; Chen, J.; Hua, Y.; Cao, M.; Zhang, L.; Li, J.; Zhang, L.; Jin, J.; Wu, C.; et al. Nitrogen-doped carbon dots as multifunctional fluorescent probes. J. Nanopar. Res. 2014, 16, 2720. [CrossRef]

27. Chu, H.X.; Hu, J.; Li, R.; Yang, Y.Q. Electrochemical aptasensor for detection of acetamiprid in vegetables with graphene aerogel-glutamic acid functionalized graphene quantum dot/gold nanostars as redox probe with catalyst. Sens. Actuators B Chem. 2019, 298, 126866-126875.

28. Gavgani, J.N.; Dehsari, H.S.; Hasani, A.; Mahyari, M.; Shalamzari, E.K.; Salehi, A.; Taromi, F.A. A room temperature volatile organic compound sensor with enhanced performance, fast response and recovery based on N-doped graphene quantum dots and poly(3,4-ethylenedioxythiophene)-poly (styrene sulfonate) nanocomposite. RSC Adv. 2015, 5, 57559-57567. [CrossRef]

29. Liu, J.; Zhang, X.L.; Cong, Z.X.; Chen, Z.T.; Yang, H. Glutathione-functionalized graphene quantum dots as selective fluorescent probes for phosphate-containing metabolites. Nanoscale 2013, 5, 1810-1815. [CrossRef]

30. Zhu, S.; Zhang, J.; Liu, X.; Li, B.; Wang, X.; Tang, S.; Meng, Q.; Li, Y.; Shi, C.; Hu, R.; et al. Graphene quantum dots with controllable surface oxidation, tunable fluorescence and up-conversion emission. RSC Adv. 2012, 2, 2717-2720. [CrossRef]

31. Li, Y.; Zhao, Y.; Cheng, H.; Hu, Y.; Shi, G.; Dai, L.; Qu, L. Nitrogen-Doped Graphene Quantum Dots with Oxygen-Rich Functional Groups. J. Am. Chem. Soc. 2012, 134, 15-18. [CrossRef]

32. Qu, D.; Zheng, M.; Du, P.; Zhou, Y.; Zhang, L.; Li, D.; Tan, H.; Zhao, Z.; Xie, Z.; Sun, Z. Highly luminescent S, N co-doped graphene quantum dots with broad visible absorption bands for visible light photocatalysts. Nanoscale 2013, 5, 12272-12277. [CrossRef] [PubMed]

33. Ruiyi, L.; Tinling, P.; Hong-xia, C.; Jinsong, S.; Zaijun, L. Electrochemical detection of cancer cells in human blood using folic acid and glutamic acid-functionalized graphene quantum dot-palladium@gold as redox probe with excellent electrocatalytic activity and target recognition. Sens. Actuators B Chem. 2020, 309, 127709. [CrossRef]

34. Zhang, J.; Li, Y.; Han, S. Simultaneous detection of iodide and mercuric ions by nitrogen-sulfur co-doped graphene quantum dots based on flow injection turn off-on chemiluminescence analysis system. Microchem. J. 2019, 147, 1141-1146. [CrossRef]

35. Hatamluyi, B.; Rezayi, M.; Beheshti, H.R.; Boroushaki, M.T. Ultra-sensitive molecularly imprinted electrochemical sensor for patulin detection based on a novel assembling strategy using Au@Cu-MOF/N-GQDs. Sens. Actuators B Chem. 2020, $318,128219$. [CrossRef] 
36. Oshima, C.; Nagashima, A. Ultra-thin epitaxial films of graphite and hexagonal boron nitride on solid surfaces. J. Phys. Condens. Matter 1997, 9, 1. [CrossRef]

37. Hong, G.; Zhao, H.-1.; Deng, H.; Yang, H.J.; Peng, H.; Liu, Y.; Chen, W. Fabrication of ultra-small monolayer graphene quantum dots by pyrolysis of trisodium citrate for fluorescent cell imaging. Int. J. Nanomed. 2018, 13, 4807-4815. [CrossRef]

38. Baskin, Y.; Meyer, L. Lattice Constants of Graphite at Low Temperatures. Phys. Rev. Lett. 1955, 100, 544. [CrossRef]

39. Novoselov, K.; Geim, A.K.; Morozov, S.; Jiang, D.; Zhang, Y.; Dubonos, S.; Grigorieva, I.; Firsov, A. Electric Field Effect in Atomically Thin Carbon Films. Science 2004, 306, 666-669. [CrossRef]

40. Peng, J.; Gao, W.; Gupta, B.K.; Liu, Z.; Romero-Aburto, R.; Ge, L.; Song, L.; Alemany, L.B.; Zhan, X.; Gao, G.; et al. Graphene Quantum Dots Derived from Carbon Fibers. Nano Lett. 2012, 12, 844-849. [CrossRef]

41. Tetsuka, H.; Asahi, R.; Nagoya, A.; Okamoto, K.; Tajima, I.; Ohta, R.; Okamoto, A. Optically tunable amino-functionalized graphene quantum dots. Adv. Mater. 2012, 24, 5333-5338. [CrossRef]

42. Tarakeshwar, P.; Manogaran, S. Ground state vibrations of citric acid and the citrate trianion-An ab initio study. Spectrochim. Acta A Mol. Biomol. Spectrosc. 1994, 50, 2327-2343. [CrossRef]

43. Gu, S.; Hsieh, C.-T.; Gandomi, Y.A.; Li, J.; Yue, X.X.; Chang, J.-K. Tailoring fluorescence emissions, quantum yields, and white light emitting from nitrogen-doped graphene and carbon nitride quantum dots. Nanoscale 2019, 11, 16553-16561. [CrossRef]

44. Jiang, Y.; Li, Y.; Li, Y.; Li, S. A sensitive enzyme-free hydrogen peroxide sensor based on a chitosan-graphene quantum dot/silver nanocube nanocomposite modified electrode. Anal. Methods 2016, 8, 2448-2455. [CrossRef]

45. Hou, X.B.; Li, Y.B.; Zhao, C. Microwave-Assisted Synthesis of Nitrogen-Doped Multi-Layer Graphene Quantum Dots with Oxygen-Rich Functional Groups. Aust. J. Chem. 2016, 69, 357-360. [CrossRef]

46. Zhang, T.P.; Wan, L.; Yuan, Y.; Duan, Y.X.; Zhang, J.M. Chemical Structure and Interlayer Distance Correlation of Graphite Oxide in the Heating Process as Revealed by In Situ Fourier Transform Infrared Spectroscopy and Wide-Angle X-ray Diffraction Techniques. Appl. Spectrosc. 2014, 68, 570-576. [CrossRef] [PubMed]

47. Wu, X.; Tian, F.; Wang, W.; Chen, J.; Wu, M.; Zhao, J.X. Fabrication of highly fluorescent graphene quantum dots using L-glutamic acid for in vitro/in vivo imaging and sensing. J. Mater. Chem. C 2013, 1, 4676-4684. [CrossRef] [PubMed]

48. Zhan, J.; Peng, R.; Wei, S.; Chen, J.; Peng, X.; Xiao, B. Ethanol-Precipitation-Assisted Highly Efficient Synthesis of Nitrogen-Doped Carbon Quantum Dots from Chitosan. ACS Omega 2019, 4, 22574-22580. [CrossRef] [PubMed]

49. Li, Y.; Hu, Y.; Zhao, Y.; Shi, G.; Deng, L.; Hou, Y.; Qu, L. An Electrochemical Avenue to Green-Luminescent Graphene Quantum Dots as Potential Electron-Acceptors for Photovoltaics. Adv. Mater. 2011, 23, 776-779. [CrossRef] [PubMed]

50. Shinde, D.; Vishal, V.M.; Kurungot, S.; Pillai, V. Electrochemical preparation of nitrogen-doped graphene quantum dots and their size-dependent electrocatalytic activity for oxygen reduction. Bull. Mater. Sci. 2015, 38, 435-442. [CrossRef]

51. Schroer, Z.S.; Wu, Y.; Xing, Y.; Wu, X.; Liu, X.; Wang, X.; Pino, O.G.; Zhou, C.; Combs, C.; Pu, Q.; et al. Nitrogen-Sulfur-Doped Graphene Quantum Dots with Metal Ion-Resistance for Bioimaging. ACS Appl. Nano Mater. 2019, 2, 6858-6865. [CrossRef]

52. Santiago, S.R.M.S.; Chang, C.-H.; Lin, T.N.; Yuan, C.T.; Shen, J.L. Diethylenetriamine-Doped Graphene Oxide Quantum Dots with Tunable Photoluminescence for Optoelectronic Applications. ACS Appl. Nano Mater. 2019, 2, 3925-3933. [CrossRef]

53. Li, H.J.; Sun, X.; Xue, F.; Ou, N.; Sun, B.-W.; Qian, D.J.; Chen, M.; Wang, D.; Yang, J.; Wang, X. Redox Induced Fluorescence On-Off Switching Based on Nitrogen Enriched Graphene Quantum Dots for Formaldehyde Detection and Bioimaging. ACS Sustain. Chem. Eng. 2018, 6, 1708-1716. [CrossRef]

54. Li, Y.; Liu, X.; Wang, J.; Liu, H.; Li, S.; Hou, Y.; Wan, W.; Xue, W.; Ma, N.; Zhang, J.Z. Chemical Nature of Redox-Controlled Photoluminescence of Graphene Quantum Dots by Post-Synthesis Treatment. J. Phys. Chem. C 2016, 120, 26004-26011. [CrossRef]

55. Li, L.; Wu, G.; Yang, G.; Peng, J.; Zhao, J.; Zhu, J.J. Focusing on luminescent graphene quantum dots: Current status and future perspectives. Nanoscale 2013, 5, 4015-4039. [CrossRef]

56. Yang, G.; Wu, C.; Luo, X.; Liu, X.; Gao, Y.; Wu, P.; Cai, C.; Saavedra, S.S. Exploring the Emissive States of Heteroatom-Doped Graphene Quantum Dots. J. Phys. Chem. C 2018, 122, 6483-6492. [CrossRef]

57. Bourlinos, A.B.; Stassinopoulos, A.; Anglos, D.; ZbpYil, R.; Karakassides, M.A.; Giannelis, E.P. Surface functionalized carbogenic quantum dots. Small 2008, 4, 455-458. [CrossRef]

58. Xu, X.; Gao, F.; Bai, X.; Liu, F.; Kong, W.; Li, M. Tuning the Photoluminescence of Graphene Quantum Dots by Photochemical Doping with Nitrogen. Materials 2017, 10, 1328. [CrossRef]

59. Kaur, M.; Kaur, M.; Sharma, V.K. Nitrogen-doped graphene and graphene quantum dots: A review onsynthesis and applications in energy, sensors and environment. Adv. Colloid Interface Sci. 2018, 259, 44-64. [CrossRef]

60. Moniruzzaman, M.; Kim, J. N-doped carbon dots with tunable emission for multifaceted application: Solvatochromism, moisture sensing, pH sensing, and solid state multicolor lighting. Sens. Actuators B Chem. 2019, 295, 12-21. [CrossRef]

61. Wu, Z.L.; Gao, M.X.; Wang, T.t.; Wan, X.Y.; Zheng, L.L.; Huang, C.Z. A general quantitative pH sensor developed with dicyandiamide $\mathrm{N}$-doped high quantum yield graphene quantum dots. Nanoscale 2014, 6, 3868-3874. [CrossRef]

62. Vercelli, B.; Donnini, R.; Ghezzi, F.; Sansonetti, A.; Giovanella, U.; La Ferla, B. Nitrogen-doped carbon quantum dots obtained hydrothermally from citric acid and urea: The role of the specific nitrogen centers in their electrochemical and optical responses. Electrochim. Acta 2021, 387, 138557. [CrossRef]

63. Wang, R.; Du, X.; Wu, Y.; Zhai, J.; Xie, X. Graphene Quantum Dots Integrated in lonophore-Based Fluorescent Nanosensors for $\mathrm{Na}^{+}$and $\mathrm{K}^{+}$. ACS Sens. 2018, 3, 2408-2414. [CrossRef] [PubMed] 
64. Choi, Y.; Kang, B.; Lee, J.; Kim, S.; Kim, G.T.; Kang, H.; Lee, B.R.; Kim, H.; Shim, S.H.; Lee, G.; et al. Integrative Approach toward Uncovering the Origin of Photoluminescence in Dual Heteroatom-Doped Carbon Nanodots. Chem. Mater. 2016, 28, 6840-6847. [CrossRef]

65. Zhu, X.; Zuo, X.; Hu, R.; Xiao, X.; Liang, Y.; Nan, J. Hydrothermal synthesis of two photoluminescent nitrogen-doped graphene quantum dots emitted green and khaki luminescence. Mater. Chem. Phys. 2014, 147, 963-967. [CrossRef]

66. Bao, L.; Zhang, Z.-L.; Tian, Z.Q.; Zhang, L.; Liu, C.; Lin, Y.; Qi, B.; Pang, D.W. Electrochemical Tuning of Luminescent Carbon Nanodots: From Preparation to Luminescence Mechanism. Adv. Mater. 2011, 23, 5801-5806. [CrossRef]

67. Dai, Y.; Long, H.; Wang, X.; Wang, Y.; Gu, Q.; Jiang, W.; Wang, Y.; Li, C.; Zeng, T.; Sun, Y.; et al. Doping: Versatile Graphene Quantum Dots with Tunable Nitrogen Doping. Part. Part. Syst. Charact. 2014, 31, 509. [CrossRef]

68. Liu, Q.; Guo, B.; Rao, Z.; Zhang, B.; Gong, J.R. Strong two-photon-induced fluorescence from photostable, biocompatible nitrogen-doped graphene quantum dots for cellular and deep-tissue imaging. Nano Lett. 2013, 13, 2436-2441. [CrossRef]

69. Qian, Z.; Ma, J.; Shan, X.; Shao, L.; Zhou, J.; Chen, J.; Feng, H. Surface functionalization of graphene quantum dots with small organic molecules from photoluminescence modulation to bioimaging applications: An experimental and theoretical investigation. RSC Adv. 2013, 3, 14571-14579. [CrossRef]

70. Zheng, X.T.; Ananthanarayanan, A.; Luo, K.Q.; Chen, P. Glowing Graphene Quantum Dots and Carbon Dots: Properties, Syntheses, and Biological Applications. Small 2015, 11, 1620-1636. [CrossRef]

71. Hu, C.F.; Liu, Y.L.; Yang, Y.H.; Cui, J.H.; Huang, Z.R.; Wang, Y.L.; Yang, L.F.; Wang, H.B.; Xiao, Y.; Rong, J.H. One-step preparation of nitrogen-doped graphene quantum dots from oxidized debris of graphene oxide. J. Mater. Chem. B 2013, 1, 39-42. [CrossRef]

72. Lin, L.; Rong, M.; Lu, S.; Song, X.; Zhong, Y.; Yan, J.; Wang, Y.; Chen, X. A facile synthesis of highly luminescent nitrogen-doped graphene quantum dots for the detection of 2,4,6-trinitrophenol in aqueous solution. Nanoscale 2015, 7, 1872-1878. [CrossRef]

73. Wang, Y.J.; Liu, Y.Q.; Gao, X.X.; Zhan, Y.S.; Pan, L.Y.; Zhang, W.K.; Fang, X.M. Surface Defect Passivation of Graphene Quantum Dots by Amino Functionalization and Photoluminescence Emission Enhancement. Acta Phys. Chim. Sin. 2016, 32, $2636-2644$. [CrossRef]

74. Ju, J.; Zhang, R.; He, S.; Chen, W. Nitrogen-doped graphene quantum dots-based fluorescent probe for the sensitive turn-on detection of glutathione and its cellular imaging. RSC Adv. 2014, 4, 52583-52589. [CrossRef]

75. Du, Y.; Guo, S. Chemically doped fluorescent carbon and graphene quantum dots for bioimaging, sensor, catalytic and photoelectronic applications. Nanoscale 2016, 8, 2532-2543. [CrossRef]

76. Fan, Z.; Li, S.; Yuan, F.; Fan, L. Fluorescent graphene quantum dots for biosensing and bioimaging. RSC Adv. 2015, 5, 19773-19789. [CrossRef]

77. Lu, H.; Li, W.; Dong, H.; Wei, M. Graphene Quantum Dots for Optical Bioimaging. Small 2019, 15, 1902136. [CrossRef] [PubMed]

78. Younis, M.R.; He, G.; Lin, J.; Huang, P. Recent Advances on Graphene Quantum Dots for Bioimaging Applications. Front. Chem. 2020, 8, 424. [CrossRef] [PubMed]

79. Shin, Y.; Lee, J.; Yang, J.; Park, J.; Lee, K.; Kim, S.; Park, Y.; Lee, H. Mass production of graphene quantum dots by one-pot synthesis directly from graphite in high yield. Small 2014, 10, 866-870. [CrossRef] 